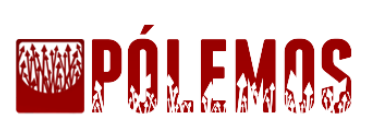

\section{O CONCEITO DE INCONSCIENTE EM LÉVI-STRAUSS REVISITADO}

\author{
Henrique Fróes
}

Mestre em Psicologia Clínica e graduando em Filosofia pela Universidade de Brasília (UnB), com especialização em Teoria Psicanalítica nesta mesma instituição.

\section{RESUMO}

O presente artigo propõe uma revisão do conceito de inconsciente forjado por Lévi-Strauss no início do desenvolvimento do pensamento estruturalista. Para isso, serão analisados textos selecionados extraídos do livro Antropologia Estrutural, bem como a Introdução à obra de Marcel Mauss, nos quais Lévi-Strauss dedica-se ao tema. A partir dessa análise, buscar-se-á apontar não só como o autor define o conceito de inconsciente, mas também as implicações teóricas e metodológicas daí advindas.

Palavras-chave: Inconsciente; Lévi-Strauss; Antropologia; Metodologia.

\begin{abstract}
This article proposes a review of the concept of the unconscious as wrought by Lévi-Strauss in the beginning of the development of the structuralistic thought. To achieve this, the article will analyze a collection of texts extracted from Structural Anthropology and the Introduction to the work of Marcel Mauss, in which Lévi-Strauss is dedicated to the theme. From this analysis, the article will try to show the definition of the concept of the unconscious given by the author and the theoretical and methodological implications arising therefrom.
\end{abstract}

Key-words: Unconscious; Lévi-Strauss; Anthropology; Methodology.

Introdução

Desde o lançamento de sua primeira grande obra, As estruturas elementares do parentesco, o antropólogo Claude Lévi-Strauss exerceu uma influência inquestionável no panorama intelectual ocidental. O pai do estruturalismo francês estabeleceu as bases de uma revolução metodológica que influenciou os mais diversos campos do saber: além da antropologia, a filosofia, a psicanálise, a crítica literária e a sociologia passaram por profundas mudanças nas décadas de 50, 60 e 70 a partir do paradigma estabelecido por Lévi-Strauss. Michel Foucault, Jacques Lacan, Roland Barthes e Luis Althusser são alguns dos autores que beberam na fonte do pensamento desenvolvido pelo autor das Mitológicas. 
A ambição do projeto straussiano é o de proporcionar às ciências sociais o mesmo rigor e formalização das ciências exatas. Para isso, apropria-se da metodologia utilizada pela linguística estrutural, que procura estabelecer leis gerais por meio da apreensão das relações internas entre os termos analisados, considerados dentro de uma noção de sistema. De autores como Ferdinand de Saussure, Roman Jakobson e Nicolas Troubetzkoy, Lévi-Strauss reteve duas importantes lições para a antropologia: a investigação de invariantes e o afastamento da noção de consciência do sujeito falante, priorizando, assim, os fenômenos inconscientes da estrutura (DOSSE, 1993). Seja por meio da análise dos sistemas de parentesco, dos mitos, da culinária, da religião ou das artes, o objetivo do trabalho de Lévi-Strauss é chegar às estruturas inconscientes que dão origem aos fenômenos em questão.

O conceito de inconsciente é, pois, fundamental para o pensamento de Lévi-Strauss e, por consequência, para toda a escola estruturalista. O objetivo desse trabalho é, por meio de uma revisão bibliográfica, mapear e identificar os usos e os sentidos que o autor dá ao conceito de inconsciente em duas de suas principais obras teóricas: o livro Antropologia estrutural e o texto Introdução à obra de Marcel Mauss, prefácio ao livro Sociologia e Antropologia, de Marcel Mauss. Nelas, Lévi-Strauss fundamenta teórica e metodologicamente sua antropologia estruturalista, passando, para isso, pela definição do conceito de inconsciente e pela especificação de sua importância metodológica, além de delimitar os objetos de sua pesquisa como fenômenos incosncientes. Também serão utilizados nessa revisão de literatura autores que comentam e criticam o pensamento de Lévi-Strauss, tais como Badcock, Aragão, Rossi, Dosse, Lepine e Merquior.

\section{O inconsciente no programa estruturalista: Introdução à obra de Marcel Mauss}

Um ano após a publicação de As estruturas elementares do parentesco, Lévi-Strauss foi convidado a escrever um prefácio a uma coletânea de textos do sociólogo e antropólogo francês Marcel Mauss. A obra do sobrinho de Durkheim é uma das bases para o desenvolvimento do pensamento straussiano, como aponta Badcock (1976):

A importância de Mauss foi que sua análise, especialmente em The Gift (Ensaio sobre a dádiva), permitiu-nos avançar do consenso normativo puramente consciente, para o sistema e comunicação estrutural e inconsciente. Para Mauss, era a lógica implícita do princípio de reciprocidade que importava mais do que a norma consciente. (BADCOCK, 1976, p. 54) 
Indo muito além de uma simples apresentação da obra em questão, o texto é utilizado para trazer à luz o programa da antropologia estruturalista. Foi um acontecimento que marcou época, como conta Dosse: “(...) (o prefácio) constituiu a primeira definição de um programa unitário proposto ao conjunto das ciências do homem desde a tentativa dos ideólogos do começo do século XIX (...).” (DOSSE, 1993, p. 47)

No texto, Lévi-Strauss ressalta, em primeiro lugar, a modernidade do pensamento de Mauss: o ineditismo dos estudos sobre as técnicas do corpo - o quanto a sociedade e a educação moldam o corpo da criança e como a cultura determina como ele será usado - e a aproximação entre etnologia e a psicanálise. Ao comentar um dos textos presentes no livro Relações reais e práticas entre a psicologia e a sociologia - o antropólogo estruturalista vai criticar os estudos da época, que se debatiam em determinar o primado do individual ou do social na explicação do comportamento humano. Um debate estéril, na opinião de LéviStrauss, que entende que a formulação psicológica não passa da tradução de uma estrutura sociológica para o plano do psiquismo individual.

Mas é preciso tomar cuidado com essa passagem do individual para o social: no caso, o autor de Tristes Trópicos critica a utilização da terminologia psiquiátrica na caracterização de fenômenos sociais. Para ele, a sociedade naturalmente se exprime simbolicamente em seus costumes e instituições; individualmente, as condutas jamais são simbólicas por elas mesmas. “O psiquismo individual não reflete o grupo, muito menos o pré-forma. Teremos legitimado suficientemente o valor e a importância dos estudos que se fazem hoje nessa direção reconhecendo que ele o completa." (LÉVI-STRAUSS (2003, p.22)

A predominância do social sobre o individual não significa o descarte do último, parte integrante do conceito de fato social total. Esse só pode ser concebido encarnado numa experiência individual. Seu caráter é tridimensional: sociológico, histórico e fisiopsicológico. Somente num indivíduo se concretizam essas três dimensões:

Portanto, é realmente verdade que, num certo sentido, todo fenômeno psicológico é um fenômeno sociológico, que o mental identifica-se com o social. Mas, num outro sentido, tudo se inverte: a prova do social, esta, só pode ser mental; dito de outro modo, jamais podemos estar certos de ter atingido o sentido e a função de uma instituição, se não somos capazes de reviver sua incidência numa consciência individual. (...) (a complementariedade entre o psíquico e o social) é dinâmica e provém de que o psíquico é ao mesmo tempo simples elemento de significação para um simbolismo que o ultrapassa, e único meio de verificação de uma realidade cujos aspectos múltiplos não podem ser apreendidos em forma de síntese fora dele (LÉVI-STRAUSS, 2003, p. 24). 
Lévi-Strauss quer chamar a atenção para o problema do sujeito e do objeto no trabalho antropológico. Para ele, a noção de fato social total ultrapassa o entendimento de que tudo o que é observado faz parte da observação: ela pressupõe que o observador torna-se também parte da observação. A objetividade do antropólogo em relação ao outro deve ser complementada pela apreensão subjetiva da experiência e dos fenômenos. Nesse processo, o etnógrafo deve se identificar com o outro, correndo sempre o risco de que sua apreensão subjetiva dos fenômenos nada possua em comum com a do outro. Esses erros de interpretação, no entanto, seriam inevitáveis caso algo não unisse as duas subjetividades em questão: o inconsciente. Segundo Lévi-Strauss, o inconsciente é o termo mediador entre dois sujeitos. Lépine esclarece o papel do inconsciente no nível metodológico do pensamento de LéviStrauss:

Isto quer dizer que o observador é o seu próprio instrumento e que ele mesmo faz parte integrante da experiência, de tal modo que o seu eu se desdobra num eu-instrumento que apreende a significação dos fenômenos culturais, identificando-se com o indígena, e num segundo eu que observa e objetiva o primeiro. Este duplo movimento de interiorização do objeto, e de objetivação do sujeito, esta passagem do subjetivo ao objetivo, exige uma mediação: a do inconsciente. (LEPINE, 1974, p. 34)

Inconsciente também é o caráter comum e específico dos fatos sociais, segundo Mauss. Como se fosse um estruturalista avant la lettre, o sobrinho de Durkheim, segundo LéviStrauss, havia constatado a semelhança entre os fenômenos sociais e os da linguagem, antes que a linguística estrutural houvesse difundido a ideia de que os fenômenos fundamentais da vida do espírito estão situados no nível do pensamento inconsciente.

Esse inconsciente, no entender de Mauss, é coletivo, mas, na opinião de Lévi-Strauss, difere radicalmente daquele proposto por Jung. Ambos consideram o inconsciente um sistema simbólico, mas, para o psiquiatra suíço, ele estaria repleto de símbolos, o que levanta a questão de origem desse substrato. Inato ou adquirido, não importa: ambos são inconcebíveis para Lévi-Strauss.

Na realidade, não se trata de traduzir em símbolos um dado extrínseco, mas de reduzir à sua natureza de sistema simbólico coisas que só escapam a ele para se incomunicabilizar. Como a linguagem, o social é uma realidade autônoma (a mesma, aliás); os símbolos são mais reais que aquilo que simbolizam, o significante precede e determina o significado. (LÉVI-STRAUSS, 2003, p. 29)

Em seguida, Lévi-Strauss vai ressaltar o caráter revolucionário do texto de Mauss, Ensaio sobre a dádiva, um dos pilares em que se baseou para desenvolver as ideias contidas em As estruturas elementares do parentesco. Para ele, o ensaio é o primeiro na história do pensamento etnológico a efetuar um esforço de transcendência da observação empírica com o 
objetivo de atingir realidades mais profundas. O social é encarado como um sistema, passível de ser dividido em partes das quais é possível estabelecer conexões, equivalências e solidariedades. O caminho aberto pelo Ensaio sobre a dádiva, no entanto, não foi levado às últimas consequências pelo próprio Mauss. Exemplo disso é a sua aceitação do conceito de hau, no caso, um conceito indígena neozelandês que seria o motivo último que explicaria e justificaria o circuito das trocas. Lévi-Strauss aponta então o erro de Mauss em ter aceito a explicação indígena como a parte que faltava na explicação do fenômeno como um todo, esquecendo-se de sua própria lição de que a unidade do todo é mais real que cada uma das partes. "O hau não é a razão última da troca: é a forma consciente sob a qual homens de uma sociedade determinada, em que o problema tinha uma importância particular, conceberam uma necessidade inconsciente cuja razão está alhures" (LÉVI-STRAUSS, 2003, p. 34). O antropólogo belga dá a receita de como deveria ter procedido Mauss em sua análise, destacando que é preciso ultrapassar as explicações formuladas pelo pensamento consciente para se alcançar a verdade inconsciente dos fenômenos, expresso nas estruturas.

Depois de ter destacado a concepção indígena, era preciso reduzi-la por uma crítica objetiva que permitisse atingir a realidade subjacente. Ora, esta tem muito menos chance de se achar em elaborações conscientes do que em estruturas mentais inconscientes que se pode atingir através das instituições e, melhor ainda, na linguagem. (LÉVI-STRAUSS, 2003, p. 35)

Lévi-Strauss esboça então uma ideia que será desenvolvida posteriormente em $O$ pensamento selvagem: o de que o pensamento humano está permanentemente buscando compreender o mundo, e que a ciência moderna e os mitos indígenas, por exemplo, realizam as mesmas operações lógicas, sendo que a diferença entre eles é mais de grau do que de natureza.

Antropologia estrutural: definição e características do inconsciente straussiano

Antropologia Estrutural é uma seleção de artigos lançada em 1958 e que tem a força de um manifesto. A obra apresenta um conjunto coerente formado por dezessete escritos: além de artigos e conferências já publicados, trazia também dois textos inéditos, que rebatiam críticas e esclarecia alguns de seus pontos de vista. Como contou Lévi-Strauss em entrevista a Didier Eribon, o projeto do livro já existia antes mesmo da publicação de Tristes Trópicos, tendo sido rejeitado então pela Editora Gallimard. A escolha do título lhe pareceu evidente:

Tinha-me reconhecido no estruturalismo tal como o praticavam os linguistas. Mas não esqueça que o estruturalismo ainda não era o que a moda fez dele. 
Queria simplesmente dizer que me situava na mesma região intelectual que Saussure, Troubetzkoy, Jakobson, Benveniste. Pelo menos era a minha ambição. (LÉVI-STRAUSS, 2005, p. 104)

Em História e etnologia, primeiro texto da coletânea, Lévi-Strauss discute as semelhanças e diferenças entre as duas disciplinas, num debate que iria atravessar todo o pensamento estruturalista. Para ele, ambas tem o mesmo objeto (a vida social), o mesmo objetivo (a melhor compreensão do homem) e métodos semelhantes. O que as distingue seriam suas perspectivas: no caso da história, a organização dos dados dá-se em relação a expressões conscientes, enquanto a etnologia o faz em relação às condições inconscientes da vida social. O fato de lidar com fenômenos coletivos de natureza inconsciente é que garante a originalidade do campo etnológico. Na visão de Lévi-Strauss, as crenças, artes, costumes e conhecimentos de um povo, entre outros fenômenos sociais, são frutos de razões inconscientes que não são alcançadas pelas explicações ou justificativas dadas por quem as pratica.

A natureza inconsciente dos fenômenos culturais assemelha-se à da linguagem. Citando Boas, Lévi-Strauss ressalta que os fenômenos inconscientes podem ser observados sem que haja a intervenção de interpretações secundárias e prega o método da linguística na comparação de dados etnográficos em busca de uma estrutura subjacente a eles. Para o autor de Tristes Trópicos, a generalização funda a comparação, e é a passagem do específico para o geral que permite a travessia do consciente para o inconsciente:

$\mathrm{Se}$, como cremos, a atividade inconsciente do espírito consiste em impor formas a um conteúdo, e se essas formas são fundamentalmente as mesmas para todos os espíritos, antigos e modernos, primitivos e civilizados (como mostra tão claramente o estudo da função simbólica tal como expressa na linguagem), é necessário e suficiente atingir a estrutura inconsciente, subjacente a cada instituição e a cada costume, para obter um princípio de interpretação válido para outras instituições e outros costumes, contanto, evidentemente, que se avance o suficiente na análise. (LÉVI-STRAUSS, 2008, p. 35)

A estrutura inconsciente pode ser diacrônica ou sincrônica, mas, mesmo a análise dessa última não pode abrir mão da história. A etnologia deve dedicar-se ao estudo dos processos históricos e das expressões conscientes dos processos sociais para, num segundo momento, eliminar, em sua análise, tudo o que eles devem ao evento e à reflexão, já que seu objetivo é “(...) atingir, para além da imagem consciente e sempre diferente que os homens formam do seu devir, um inventário de possibilidades inconscientes (...)" (LÉVI-STRAUSS, 2008, p. 37) 
O texto $A$ análise estrutural em linguística e antropologia é considerado por MERQUIOR (1991) o capítulo principal de Antropologia Estrutural. Nele, Lévi-Strauss vai apontar a fonologia como um modelo de ciência a ser seguido por outras ciências sociais. Citando Troubetzkoy, resume os procedimentos fundamentais do método fonológico, sendo o primeiro deles a passagem do "estudo dos fenômenos linguísticos conscientes para o de sua infraestrutura inconsciente" (LÉVI-STRAUSS, 2008, p. 45). Além disso, a fonologia toma como base de análise as relações entre os termos, introduz a noção de sistema e busca a descoberta de leis gerais. No entender de Lévi-Strauss, alguns problemas estudados pelos sociólogos são análogos aos dos linguistas fonólogos. Os sistemas de parentesco, por exemplo, se assemelham aos sistemas fonológicos, pois ambos seriam elaborados pelo espírito no mesmo estágio, o do pensamento inconsciente.

Em Linguagem e Sociedade, Lévi-Strauss questiona a opinião de Wiener da impossibilidade e da irrelevância do uso de métodos matemáticos de predição nas ciências sociais devido à influência do observador nos fenômenos observados e a falta de séries estatísticas extensas dos mesmos. Para Lévi-Strauss, a linguística supera essas limitações, devido, principalmente, ao caráter inconsciente da linguagem:

Primeiro, quase todos os comportamentos linguísticos se situam no nível do pensamento inconsciente. Ao falarmos, não temos consciência das leis sintáticas e morfológicas da língua. Além disso, não temos consciência dos fonemas que utilizamos para diferenciar o sentido das palavras; e temos ainda menos consciência - supondo que possamos tê-las às vezes - das oposições fonológicas que permitem analisar cada fonema em elementos diferenciais. Finalmente, a falta de apreensão intuitiva persiste mesmo quando formulamos as regras gramaticais ou fonológicas de nossa língua. (LÉVI-STRAUSS, 2008, p. 68)

Para Lévi-Strauss, a linguagem parece ser o único fenômeno social que se presta a um estudo científico capaz tanto de explicar como foi formada como de prever as modalidades de sua evolução futura. Isso graças à fonologia e ao seu método capaz de atingir realidades objetivas para além das manifestações conscientes e históricas da língua. Tais realidades objetivas "consistem em sistemas de relações, que são o produto da atividade inconsciente do espírito" (LÉVI-STRAUSS, 2008, p. 70). O autor do texto interroga-se, então, se esse mesmo tipo de conhecimento pode ser adquirido a partir do estudo de outros fenômenos sociais com o mesmo método. Em caso afirmativo, seria possível inferir que diversas formas de vida social não passariam de projeções "no plano do pensamento consciente e socializado, das leis universais que regem a atividade inconsciente do espírito" (LÉVI-STRAUSS, 2008, p. 70). 
Como exemplo desse tipo de estudo, Lévi-Strauss cita o trabalho de Kroeber sobre a moda, considerada um fenômenos social intimamente ligado à atividade inconsciente e que, a partir das relações entre os elementos do vestuário, é passível de um estudo científico.

De maneira especulativa, Lévi-Strauss propõe a hipótese de que seria possível se chegar a um código universal capaz de expressar as propriedades comuns entre fenômenos sociais e a linguagem. O objetivo seria confirmar se as diferentes modalidades de comunicação (linguagem, regras de parentesco) estão ou não ligadas a estruturas inconscientes similares. Essa similaridade entre fenômenos sociais e linguagem permitiria compreender certas analogias entre linguagem, arte, direito e religião. Além disso:

(...) poderíamos, afinal, esperar superar um dia a antinomia entre a cultura, coisa coletiva, e os indivíduos que a encarnam, já que, nessa nova perspectiva, a suposta "consciência coletiva" se reduziria a uma expressão, no nível do pensamento e dos comportamentos individuais, de certas modalidades temporais das leis universais em que consiste a atividade inconsciente do espírito. (LÉVI-STRAUSS, 2008, p. 78)

Em Linguística e Antropologia, Lévi-Strauss discute as relações entre língua e cultura, ambas sendo manifestações do que ele denomina espírito humano e que as atravessa. Porém, o autor se questiona sobre o nível em que se deve colocar o pesquisador para buscar a correlação entre língua e cultura e quais os objetos que podem servir para estabelecer essa aproximação entre diferentes ordens. O texto cita o exemplo de um antropólogo que tentou, sem sucesso, relacionar a existência de dois diferentes prefixos para designar o gênero feminino em determinado povo com diferentes comportamentos sociais. Para Lévi-Strauss, é impossível estabelecer esse tipo de correlação no nível dos comportamentos, já que "não se situam no mesmo plano que as categorias inconscientes do pensamento, a que teria sido preciso chegar primeiro analiticamente, para compreender a função diferencial dos dois prefixos." (LÉVI-STRAUSS, 2008, p. 84). Atitudes sociais e estruturas linguísticas estão em níveis diferentes, afirma Lévi-Stráuss, que defende como hipótese de trabalho o fato de que certas correlações entre linguagem e cultura podem ser extraídas entre determinados aspectos e em determinados níveis, mas que ainda é preciso descobrir quais são os limites e as possibilidades de tais pesquisas.

Esse mesmo tema é retomado no Posfácio aos capítulos III e IV. O autor explica que o objetivo da antropologia estrutural não é comparar, por exemplo, estruturas fonológicas ou lexicais da língua francesa com a estrutura da sociedade francesa. $\mathrm{O}$ objeto de pesquisa seria, nesse exemplo, expressões parciais - como sistema de parentesco, ritos, mitologia, artes porém privilegiadas, de uma totalidade chamada sociedade francesa, em busca de 
propriedades comuns e suas relações.

Em outro exemplo de uma análise estrutural, Lévi-Stráuss utiliza a culinária como possível objeto de estudo. A partir dele, poderiam ser estabelecidas relações de oposição entre as matérias-primas utilizadas (endógenas ou exógenas), a base da refeição e os acompanhamentos (central ou periférico) e a característica do sabor (marcado ou não marcado), entre muitas outras. Após estabelecer essas estruturas diferenciais, a análise vai então buscar determinar se essas estruturas podem ser encontradas em outros campos da mesma sociedade ou de sociedades diferentes. Caso sejam, o pesquisador poderia concluir que atingiu um valor significativo das atitudes inconscientes de determinada sociedade (ou sociedades).

Em A noção de estrutura em etnologia, o autor pretende explicar a metodologia de sua antropologia estruturalista. Num primeiro nível, está a construção de modelos que permitem descrever e explicar um grupo de fenômenos. Esses modelos podem ser conscientes ou inconscientes. A preferência é pelos últimos, já que os modelos conscientes, também considerados como "normas", são geralmente "pobres" devido à sua função de perpetuar crenças e costumes. Para Lévi-Strauss, os modelos conscientes constituem um obstáculo entre o observador e seu objeto, impedindo-o de captar a estrutura profunda.

Mesmo assim, o etnólogo deve prestar atenção aos modelos construídos pelas sociedades primitivas. Lévi-Strauss aponta que Mauss e Durkheim entenderam o valor das teorias emanadas dos indígenas por constituírem uma melhor via de acesso às categorias inconscientes do pensamento indígena do que as teorias construídas pelos antropólogos. No entanto, ambas correm o risco de permanecer igualmente distantes da realidade inconsciente.

O texto A Eficácia Simbólica é um dos mais importantes na obra de Lévi-Strauss a tratar do tema do inconsciente. Nele, o antropólogo belga tenta estabelecer relações entre o xamanismo e a psicanálise. Para isso, parte da análise de um canto mágico do povo Cuna destinado a auxiliar num parto difícil. Lévi-Strauss explica a eficácia do processo xamânico por meio do fornecimento à paciente de uma linguagem pela qual ela possa expressar seus estado e ordenar uma experiência que, de outro modo, parece ininteligível. Esse processo é comparado ao da psicanálise:

Em ambos os casos, propõem-se trazer à consciência conflitos e resistências que até então haviam permanecido inconscientes, seja por terem sido recalcados por outras forças psicológicas, seja - é o caso do parto - em razão de sua própria natureza, que não é psíquica e sim orgânica, ou até simplesmente mecânica. Também em ambos os casos, os conflitos e resistências se dissolvem, não porque o paciente deles vá tomando progressivamente conhecimento, real ou 
suposto, mas porque esse conhecimento torna possível uma experiência específica, na qual os conflitos se realizam numa ordem e num plano que permitem seu livre desenrolar e conduzem ao seu desenlace. (LÉVI-STRAUSS, 2008, p. 214)

Algumas diferenças entre xamanismo e psicanálise são ressaltadas, como os diferentes papéis desempenhados pelo xamã - que assume o papel de protagonista e herói do processo, com o qual o paciente deve identificar-se - e pelo psicanalista. Também diferem no tipo de mito utilizado durante a experiência de reconstruir e reviver uma narrativa: numa, o paciente recebe um mito do exterior de caráter social, noutra, é um mito individual construído a partir do passado do paciente.

Mais que as diferenças, Lévi-Strauss advoga a semelhança entre os dois processos de cura. Para o autor, a comprovação da hipótese de que as doenças e distúrbios mentais tenham uma causa fisiológica possibilitaria tomar como semelhantes a cura xamânica e a psicanalítica:

Tratar-se-ia, em ambos os casos, de induzir uma transformação orgânica, que consiste essencialmente numa reorganização estrutural, levando o paciente a viver intensamente um mito, ora recebido, ora produzido, cuja estrutura seria, no nível do psiquismo inconsciente, análoga àquela cuja formação se quer determinar no nível do corpo. (LÉVI-STRAUSS, 2008, p. 217)

Para Lévi-Strauss, o trauma provocado por uma situação específica decorre da capacidade do fato em promover uma cristalização afetiva nos moldes de uma estrutura preexistente, análoga à estrutura do mito. São essas estruturas que formam o inconsciente, entendido como um termo com a qual se designa a função simbólica. Na famosa definição do autor:

O inconsciente (...) é sempre vazio. Ou, mais precisamente, é tão alheio às imagens quanto o estômago aos alimentos que o atravessam. Órgão de função específica, limita-se a impor leis estruturais, que lhe esgotam a realidade, a elementos esparsos que lhe vêm de fora - pulsões, emoções, representações, lembranças. (LÉVI-STRAUSS, 2008, p. 219)

Garcia-Roza esclarece essa passagem que tanta influência exerceu sobre o campo psicanalítico:

O que Lévi-Strauss nos diz é que a cultura é um conjunto de sistemas simbólicos e que esses sistemas simbólicos não são constituídos a partir do momento em que traduzimos um dado externo em símbolos, mas, ao contrário, é o pensamento simbólico que constitui o fato cultural ou social. Só há o social porque há o simbólico. Esse simbólico, Lévi-Strauss identifica-o com a função simbólica ou, o que vem a dar no mesmo, com as leis estruturais do inconsciente. (GARCIA-ROZA, 1994, p. 175)

Rossi (1974) lembra a influência kantiana na concepção de inconsciente de léviStrauss. O próprio Lévi-Strauss reconheceu essa proximidade, definindo seu trabalho como 
uma transposição para o campo antropológico da investigação kantiana sobre o problema do conhecimento. "Na verdade, ele quer descobrir aquelas categorias ou propriedades fundamentais que, de acordo com Kant, sempre condicionam a mente humana." (ROSSI, 1973, p. 30, tradução nossa)

\section{Conclusão}

Como afirma ROSSI (1973), a noção de que estruturas inconscientes são a base dos fenômenos culturais é a hipótese fundamental da antropologia estrutural. O conceito de inconsciente torna-se, então, central no pensamento de Lévi-Strauss e também para o que ele entende como antropologia: como foi visto, os fenômenos coletivos de natureza inconsciente são os verdadeiros objetos da antropologia, diferenciando-a, assim, da história.

O inconsciente também tem valor fundamental na metodologia etnográfica. É ele que fornece as condições para o trabalho do antropólogo, servindo de mediador entre este e o outro. Pode-se considerá-lo o denominador comum entre os dois sujeitos dessa relação, além de referencial de veracidade das interpretações do antropólogo.

Nesse estudo, identificou-se que Lévi-Strauss encontrou as bases teóricas para o seu conceito de inconsciente tanto nos trabalhos sociológicos de Mauss quanto na linguística estrutural de Jakobson e Troubetzkoy. O primeiro, por meio de seu conceito de fato social total. Os linguistas, pela busca da infraestrutura inconsciente em detrimento dos fenômenos conscientes. A linguística forneceu também um método para a antropologia estrutural, com a ideia de sistema, o foco nas relações entre os termos e a busca pelo estabelecimento de leis gerais. O método straussiano pressupõe, também, a construção de modelos, dando preferência aos de caráter inconsciente.

O autor de Antropologia estrutural entende que, assim como a linguagem, outros fenômenos sociais são passíveis de uma análise capaz de atingir realidades objetivas constituídas por sistemas de relação que são fruto da atividade inconsciente do espírito. A ambição final de Lévi-Strauss é superar a antinomia cultura versus indivíduo, reduzindo a consciência coletiva a uma mera expressão no sujeito de determinadas modalidades temporais de leis universais inconscientes.

Lévi-Strauss também concebe o inconsciente como um órgão. Um órgão vazio, comparável ao estômago, que não se confunde com o alimento que por ele passa. O

\footnotetext{
1 "In fact, he wants to discover those 'categories' or fundamental properties which according to Kant always constrain the human mind"
} 
inconsciente, assim, tem como única função impor leis estruturais aos elementos externos. Diferentemente do conceito de inconsciente dado por Freud, o autor das Mitológicas enfatiza "a prioridade da forma sobre o conteúdo, o que implica numa prioridade da estrutura (sincrônico) sobre a perspectiva diacrônica”, como resume ARAGÃO (1991, p. 161).

\section{Referências bibliográficas}

ARAGÃO, Luiz Tarlei de. O inconsciente em Claude Lévi-Strauss ou a dimensão inconsciente nos fenômenos culturais. In: KNOBLOCH, Felicia (org.) O inconsciente: várias leituras. São Paulo: Escuta, 1991.

BADCOCK, Christopher Robert. Lévi-Strauss: estruturalismo e teoria sociológica. Rio de Janeiro: Zahar Editores, 1976.

DOSSE, François. História do estruturalismo, v.1: o campo do signo, 1945-1966. São Paulo: Ensaio; Campinas, SP: Editora da Universidade Estadual de Campinas, 1993.

LEPINE, Claude. O inconsciente na antropologia de Lévi-Strauss. São Paulo: Ática, 1974.

LÉVI-STRAUSS, Claude. Introdução à obra de Marcel Mauss. In: MAUSS, Marcel. Sociologia e Antropologia. São Paulo: Cosac Naify, 2003.

LÉVI-STRAUSS, Claude. Antropologia estrutural. São Paulo: Cosac Naify, 2008.

LEVI-STRAUSS, Claude. De perto e de longe / Claude Lévi-Strauss, Didier Eribon. São Paulo: Cosac Naify, 2005.

MERQUIOR, José Guilherme. De Praga a Paris. Rio de Janeiro: Nova Fronteira, 1991.

ROSSI, Ino. The Unconscious in the anthropology of Claude Lévi-Strauss. American Anthropologist, Arlington, VA, vol. 75, n. 1, pgs. 20 - 48, 1973. 